\title{
Environmental damage from the combustion of fuels: challenges and methods of economic assessment
}

\author{
E. Magaril, L. Abrzhina \& M. Belyaeva \\ Department of Environmental Economics, \\ Ural Federal University, Russia
}

\begin{abstract}
Nowadays the assessment of caused and prevented environmental damage according to Russian methodology requires the determination of the negative impacts of polluting toxic substances and energy emissions, which lead to the deterioration of the environment. Herewith, other types of negative impacts that the combustion of hydrocarbon fuels can cause are ignored. The purpose of this paper is to substantiate a methodological approach to the assessment of the environmental damage caused by hydrocarbon fuel combustion.

Research has revealed that an economical assessment of the environmental damage to the atmospheric air caused by fuel combustion requires a consideration of the negative impacts of not only toxic substance emissions but also the consumption of atmospheric oxygen and the adverse effects of carbon dioxide emissions on the environment. This will ensure more reliability and objectivity of the assessment. The dynamics of energy resources consumption and carbon dioxide emissions, both in Russia and globally, were analyzed. It was concluded that one of the priority problems in Russia is to reduce $\mathrm{CO}_{2}$ emissions from vehicles. This problem can be solved by improving the quality of gasoline and diesel fuel which, with invariable structure of vehicle fleet, will ensure less environmental damage from carbon dioxide emissions caused by motor fuel combustion along with the reduction of gasoline and diesel fuel consumption.

Keywords: environmental damage, pollution, methods of environmental damage assessment, energy resources consumption.
\end{abstract}




\section{Introduction}

According to the statistics, several hundred million tons of pollutants are emitted into the atmosphere annually. The concentration of toxic substances in the air of large cities is ten times or more above the threshold limit value (TLV). Average annual, or permanent, pollutant concentrations above the TLV were registered in more than 200 Russian cities. In all of these cases, $70-90 \%$ of city air pollution is caused by road transport, which is one of the motor fuels' consumers.

It is known that the assessment of pollution damage means the determination of economic and non-economic losses connected to the negative consequences of mankind's impact. They are evaluated in monetary terms: money is regarded not only as an economic indicator but also as a conditional measure of social and environmental damages. Currently, the negative impact from the combustion of hydrocarbon fuels in stationary and mobile sources cannot be completely evaluated, which leads to an imperfect compensation of environmental damage by responsible parties. With the constant increase in fuel and energy resources consumption, the problem of enhancing the approach to the environmental damage from fuel combustion assessment becomes quite urgent.

\section{Substantiation of the method for assessing environmental damage from the combustion of fuel}

Environmental damage in the OECD countries is determined mainly on the basis of equivalent resources analysis, by means of which the needs and costs of the regeneration of damaged natural resources or services are estimated. The proportions of compensation work can be determined by legislation or competent authorities depending on such criteria as technical expediency and efficiency. In the USA, the damage of natural resources is estimated as cost measures for the elimination of any negative consequences. The US legislation considers damage relating to harm, destruction and loss of natural resources, including the estimated costs for assessing the scale of such harm, destruction and loss. However, traditionally only lands, surface waters, wild animals and fish are regarded as resources. Only in the USA does this list include atmospheric air and other resources, moreover, it is limited to state-owned resources as opposed to private resources. Damage to private resources is regulated in terms of traditional responsibility [1].

The Russian methodology for assessing prevented environmental damage takes into consideration the negative impact of anthropogenic toxic pollutants and energy emissions into the environment, which lead to the deterioration of its state in terms of the socio-economic interests of the community. According to the "Prevented Environmental Damage Identification Methodology" [2] the assessment of the scale of prevented environmental damage to the atmospheric air is conducted on the basis of the indicator of specific damage for the economic district, representing the specific cost estimation of damage from emission of a mass unit of pollutants emitted into the atmospheric air, taking into account their relative toxicity. The same method is also used for assessing pollution damage, eqn. (1): 


$$
D_{t s}^{e l}=d_{s p} \cdot \sum_{i=1}^{N} G_{i} \cdot K_{i} \cdot K_{e}
$$

where $D_{t s}^{e l}$ is environmental damage from toxic substances emission to the atmospheric air, rubles per year; $d_{s p}$ is the index of specific atmospheric air damage caused by the emission of a unit of reduced mass of a pollutant for the economic district of the Russian Federation, rubles per conventional ton; $G_{i}$ is the actual mass of the i-th pollutant during the reporting period, calculated in tons; $K_{i}$ is the coefficient of relative environmental and economic risk of the $\mathrm{i}$-th pollutant; $K_{e}$ is the coefficient of the environmental situation and environmental significance of the state of the atmospheric air for the given district.

It should be noted that the main component of industrial and transport emissions is carbon dioxide, which is regarded as non-toxic and thus its impact is not considered in the assessment on the basis of the method discussed previously. An increase in the $\mathrm{CO}_{2}$ concentration in the atmosphere is in direct relation to an increase in the consumption of fossil fuels, of which resources are limited and which also contribute to global climate change. The direct relation between $\mathrm{CO}_{2}$ emissions and hydrocarbon fuels consumption is an objective fact, whereas the relation to global warming is a subject of scientific discussion. It is important to note that $\mathrm{CO}_{2}$ emissions correlate with emissions of toxic substances and indirectly characterize the dynamics of the scale of pollution. Thus, $\mathrm{CO}_{2}$ emissions appear to be a peculiar indicator of the extent of the negative impact on the environment caused by fuel combustion $[3,4]$.

Given the seriousness of the negative impact of increasing $\mathrm{CO}_{2}$ emissions to the atmospheric air, it is expedient to assess, along with the environmental damage from toxic pollutants emissions to the atmospheric air, environmental damage from anthropogenic emissions of $\mathrm{CO}_{2}$ to the atmosphere. We suggest considering a pecuniary valuation of the negative changes in the environment and the consequences of such an impact caused by carbon dioxide emissions with industrial and transport emissions to the atmospheric air, as environmental damage from $\mathrm{CO}_{2}$ emissions. Environmental damage from $\mathrm{CO}_{2}$ emissions include losses related to the reduction of fossil fuel resources, the greenhouse effect and costs for the reduction and elimination of such an impact.

To assess the environmental damage from $\mathrm{CO}_{2}$ emissions, $D_{\mathrm{CO}_{2}}^{e l}$, the following method is proposed. Environmental damage caused by $\mathrm{CO}_{2}$ emissions from fossil fuel combustion can be estimated using the formula:

$$
\mathrm{D}_{\mathrm{CO}_{2}}^{e l}=d_{\mathrm{CO}_{2}} \cdot G_{\mathrm{CO}_{2}} \cdot J_{d}
$$

where $d_{\mathrm{CO}_{2}}$ is specific environmental damage from emissions to the atmospheric air of 1 ton of carbon dioxide, rubles per ton; $G_{\mathrm{CO}_{2}}$ is the actual mass of carbon dioxide emitted to the atmospheric air in the reporting period, calculated in tons; 
$J_{d}$ is a deflator index used for a damage index calculation from current to base (comparable) price.

We propose to adopt for Russia a cost of 1 ton equivalent of $\mathrm{CO}_{2}$ equal to 400 rubles in accordance to The State Program of the Russian Federation "Energy Conservation and Increase of Energy Effectiveness until the Year 2020" [5] as a value of the specific environmental damage from the emission of 1 ton of carbon dioxide.

On the other hand, any reaction of organic fuel oxidation followed by carbon dioxide emission requires oxygen. Atmospheric oxygen is used in many technological and industrial processes. Besides, consumption of this important natural resource in technogenic use is incomparably higher than for breathing. According to certain estimates [6], an imbalance of 10 times and more exists globally between the volume of atmospheric oxygen consumption and its reproduction. In accordance with the research of Russian scientists, a considerable decrease in the concentration of oxygen in the breathing area occurs during rush hour on central city streets, which accounts for $18.6 \%$ or less. However, at the present time environmental damage caused by anthropogenic oxygen consumption is not assessed. We suggest the consideration of a pecuniary valuation of the negative changes in the environment caused by the consumption of oxygen in technological and industrial processes and the consequences of such changes as environmental damage from anthropogenic oxygen consumption.

To assess environmental damage from oxygen consumption caused by organic fuel combustion $D_{O_{2}}^{e l}$ the following approach is proposed, eqn. (3):

$$
D_{O_{2}}^{e l}=C_{r} \cdot G_{O_{2}} \cdot J_{D}=C_{r} \cdot G_{f} \cdot \alpha \cdot 0.23 \cdot J_{D}
$$

where $C_{r}$ is a replacement cost of 1 ton of free oxygen, which is calculated as a total amount of the costs for realization of the complex of forestry measures, correlated with free oxygen produced by forest, rubles per ton; $G_{O_{2}}$ is the real mass of consumed oxygen during the reporting period, calculated in tons; $G_{f}$ is the real mass of consumed fuel during the reporting period, calculated in tons; $\alpha$ is the excess air coefficient (which is different for different types of hydrocarbon fuels); 0.23 is the oxygen content in the air (mass); $J_{d}$ is the deflator index used to convert the value of environmental damage from the current price to base (comparable) price.

According to the latter, we assume that the economical assessment of the environmental damage to the atmospheric air from organic fuel combustion necessitates taking into consideration the negative impact of the emissions of not only toxic pollutants, but also of carbon dioxide and atmospheric oxygen consumption. Total environmental damage can be assessed using the following method:

$$
D^{e l}=D_{t s}^{e l}+D_{\mathrm{CO}_{2}}^{e l}+D_{\mathrm{O}_{2}}^{e l}
$$


Obviously, the proposed methodology can be used for the economical assessment of the atmospheric air damage by stationary pollution sources, as well as the mobile ones.

\section{Carbon dioxide emission in the context of the problem of the growing consumption of fuel and energy resources}

On the basis of the data on hydrocarbon energy resources consumption [7], the evolution of $\mathrm{CO}_{2}$ emissions to the atmosphere from anthropogenic sources of fuel combustion has been estimated. The general formula to calculate carbon dioxide emissions from organic fuel combustion is the following:

$$
G_{\mathrm{CO}_{2}}=3.67 \cdot G_{f} \cdot \frac{C}{100},
$$

where $G_{f}$ is the mass of fuel consumed in the year (fuels are differentiated in type); $C$ is the percentage of carbon content in the given type of fuel; 3.67 is the coefficient obtained by converting carbon into carbon dioxide emissions from fuel combustion.

Statistical information on natural gas was converted from volume to mass data. For coal consumption, the data given in million tons oil equivalent was converted into million tons with the use of coefficients calculated separately for each year from the ratio of statistical information on coal production (the coefficient variation is conditioned by averaged coal quality variation).

Fig. 1 shows the results of the estimated carbon dioxide emissions dynamics per $1 \mathrm{~km}^{2}$ of the Earth surface (on the basis of the surface data [8]) from the combustion of oil, gas, coal and from total hydrocarbon fuel consumption.

The presented analysis shows an increase in the global consumption of energy resources, which leads to an increase in carbon dioxide emissions.

This inevitably leads to an increase in the negative impact on the environment in the world. Particularly, an increase in $\mathrm{CO}_{2}$ emissions along with deforestation (fig. 2) aggravates the problem of the growing greenhouse gases content in the atmosphere, which causes climate change on the planet.

The results of estimation for the dynamics of specific carbon dioxide emission from hydrocarbon fuels consumption in Russia (based on the fuel consumption data [9]) per $1 \mathrm{~km}^{2}$ of the Russian Federation lands area are shown in table 1 .

A decrease in carbon dioxide emissions in Russia is related to a decrease in energy resources consumption, which is due to a setback in production in the early 1990s.

It should be noted that the specific emissions per land area unit in Russia are significantly higher than the average global specific emissions, as shown in fig.1, table 1 . This is related to a number of reasons, such as severe climatic conditions on the greater part of the territory which cause high energy consumption and to a greater extent, a high specific energy-output ratio. 
1110 Energy Production and Management in the 21st Century, Vol. 2

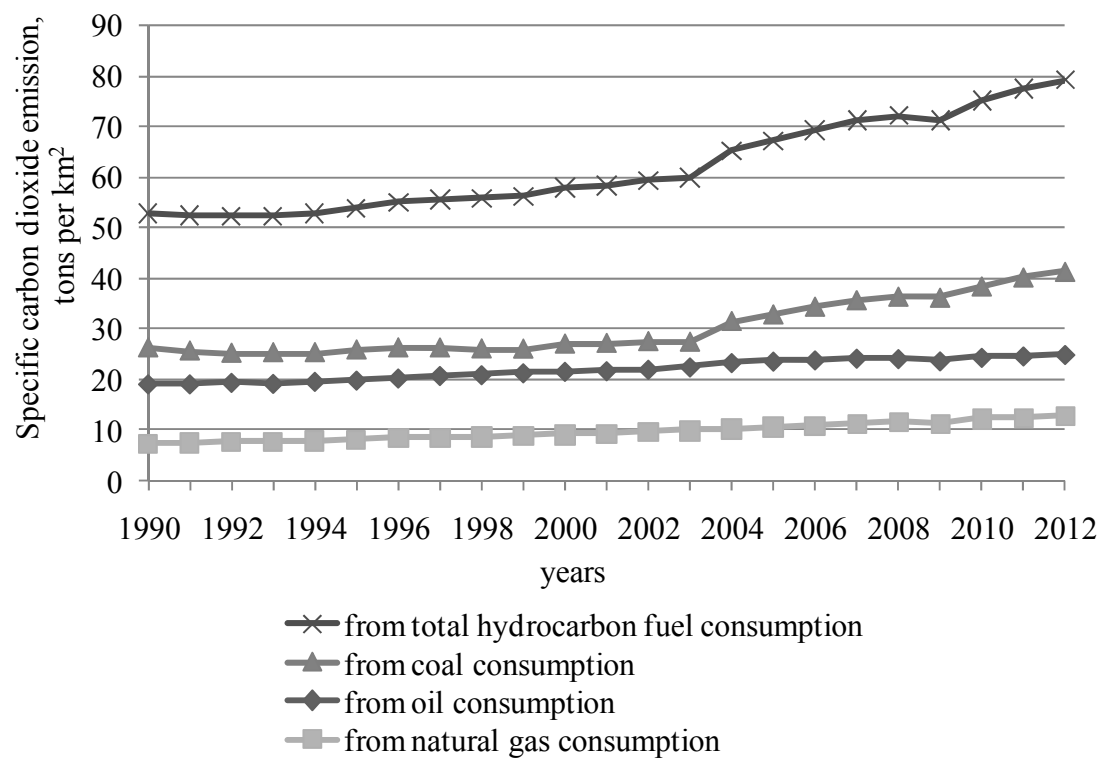

Figure 1: Specific carbon dioxide emissions per $1 \mathrm{~km}^{2}$ of the Earth's surface.

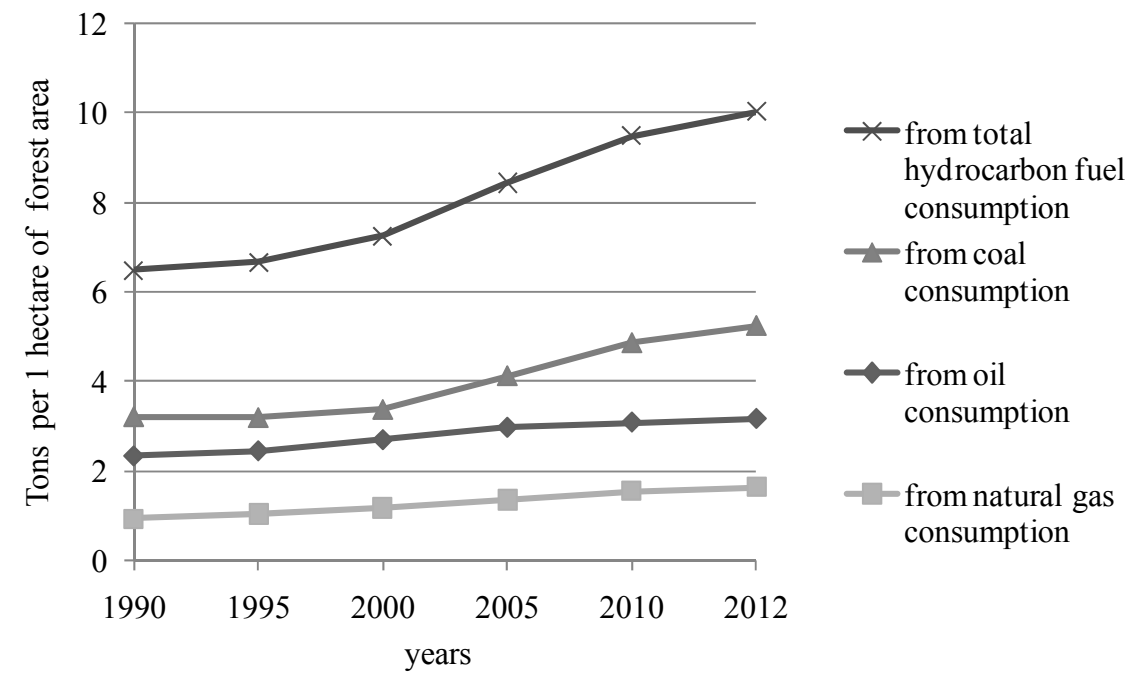

Figure 2: Specific carbon dioxide emissions per 1 hectare of forest area in the world. 
Table 1: Dynamics of carbon dioxide emissions from the consumption of fuel and energy resources in Russia.

\begin{tabular}{|c|c|c|c|c|c|}
\hline \multirow{2}{*}{$\begin{array}{l}\text { Fuel and } \\
\text { energy } \\
\text { resources }\end{array}$} & \multicolumn{5}{|c|}{$\begin{array}{l}\text { Carbon dioxide emissions, million tons/specific emissions, tons per } \\
\mathrm{km}^{2} \text { of the Russian Federation land area }\end{array}$} \\
\hline & 1992 & 1997 & 2002 & 2007 & 2012 \\
\hline Oil & $728.2 / 42.65$ & $397.6 / 23.29$ & $377.6 / 22.12$ & $380.7 / 22.30$ & $454.7 / 26.59$ \\
\hline Natural gas & $795.2 / 46.57$ & $695.1 / 39.10$ & $722.3 / 42.30$ & $817.2 / 48.56$ & $818.3 / 47.86$ \\
\hline Coal & $\begin{array}{l}1020.0 / \\
59.73\end{array}$ & $651.5 / 40.77$ & $651.6 / 38.16$ & $574.1 / 33.62$ & $578.2 / 33.82$ \\
\hline Total & $\begin{array}{l}2543.4 / \\
148.95\end{array}$ & $\begin{array}{l}1761.5 / \\
103.16\end{array}$ & $\begin{array}{l}1751.6 / \\
102.58\end{array}$ & $\begin{array}{l}1783.9 / \\
104.47\end{array}$ & $\begin{array}{l}1851.2 / \\
108.27\end{array}$ \\
\hline
\end{tabular}

\section{Environmental damage caused by carbon dioxide emissions from hydrocarbon fuels consumption by vehicles}

\subsection{Automobile contribution to carbon dioxide emissions}

Transport is one of the main consumers of oil products. Having calculated the contribution of transport to global carbon dioxide emissions, International Energy Agency states in its most optimistic of the Accelerated Technology scenarios that transport would be responsible for $62 \%$ in decreasing oil consumption [10]. Gasoline and diesel fuel combustion caused by automobiles' operation brings considerable harm to the environment, by both the toxic substances pollution and carbon dioxide emissions, which contributes $73.5 \%$ to the total transport $\mathrm{CO}_{2}$ emission structure. The world vehicle fleet is growing continuously (and already in 2010 exceeded 1 billion), therefore increasing motor fuels consumption.

Consequently, an increase in fuel efficiency of automobiles, which leads to relevant $\mathrm{CO}_{2}$ emission reduction, is one of the priorities of the international community in the context of the necessity to reasonably use unrenewable energy sources [11]. In Russia during the period of the decline in industrial production after 1990, the vehicle fleet was rapidly increasing (table 2), with almost no improvement in the quality of fuels consumed [3, 4]. It has led to an increase in carbon dioxide emissions by automobile transport (fig. 3, calculated on the basis of the data on fuels consumption [12]).

Gasoline combustion contributes the main share of $\mathrm{CO}_{2}$ emissions by automobiles in Russia, which consumes liquid motor fuels. Alongside with it, Russia is on the first place in the world by the explored proved reserves of gas, which creates vast potential for a transition to environmentally friendly gas fuel.

It is important to note that diesel fuel, which is produced by the oil-refining industry in significantly larger amounts than gasoline, is not only consumed by automobiles, but also railway and water transport, military equipment and farm machinery. Considering this, the gross carbon dioxide emissions from the combustion of diesel fuel that are produced annually are higher than those of 
gasoline. In 2012 Russian oil refineries produced $38.2 \mathrm{mln}$ tons of gasoline and $69.3 \mathrm{mln}$ tons of diesel fuel [13]. Carbon dioxide emissions from their combustion made up 119.2 and $221.3 \mathrm{mln}$ tons respectively.

Table 2: Dynamics of vehicle numbers in the Russian Federation, in thousands of units [14].

\begin{tabular}{|l|l|l|l|l|l|l|l|l|l|}
\hline \multirow{2}{*}{ Item } & \multicolumn{10}{|c|}{ Years } \\
\cline { 2 - 10 } & 2000 & 2005 & 2006 & 2007 & 2008 & 2009 & 2010 & 2011 & 2012 \\
\hline Trucks & 4401 & 4848 & 4929 & 5168 & 5349 & 5323 & 5414 & 5545 & 5712 \\
\hline Buses* & 640 & 792 & 824 & 882 & 894 & 896 & 894 & 902 & 925 \\
\hline Cars & 20353 & 25570 & 26794 & 29405 & 32021 & 33084 & 34354 & 36415 & 38748 \\
\hline Total & 25394 & 31210 & 32547 & 35455 & 38264 & 39303 & 40662 & 42862 & 45385 \\
\hline
\end{tabular}

* according to [15].

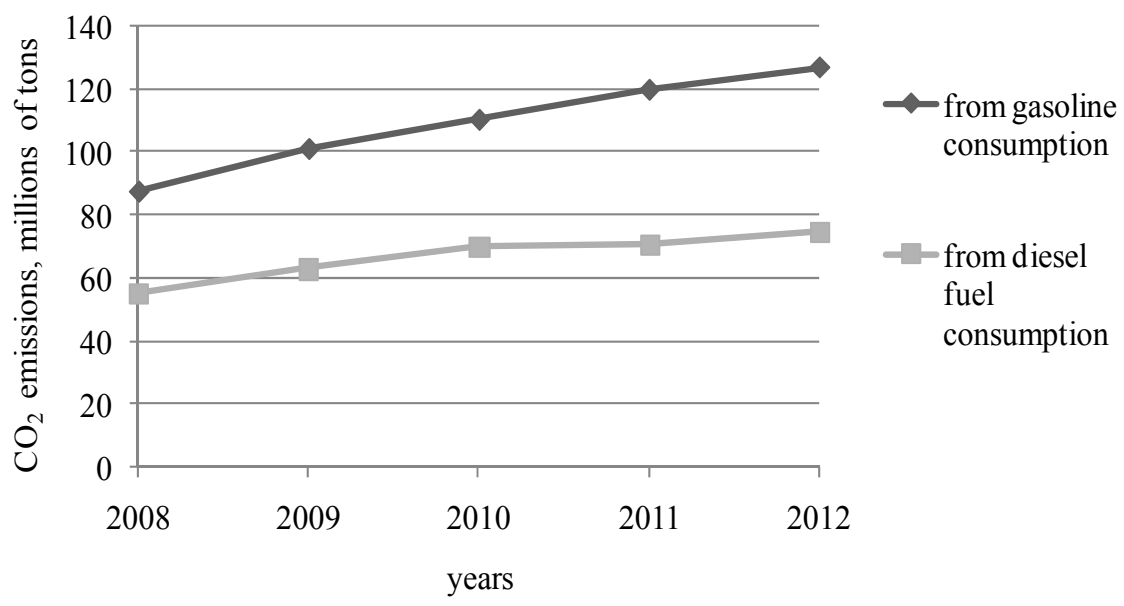

Figure 3: Dynamics of carbon dioxide emissions from motor fuels consumption by auto transport in Russia.

\subsection{Assessment of the environmental damage caused by carbon dioxide emissions from hydrocarbon fuels consumption by automobiles in Russia}

Based on the proposed methodology to assess the environmental damage caused by carbon dioxide emissions, we have carried out an economic assessment of the dynamics of environmental damage, considering the carbon dioxide that is generated in the combustion of gasoline and diesel fuel produced in Russia for the period 2003-2012, presented in fig. 4.

Fig. 5 represents the result of the economic assessment of the dynamics of the environmental damage caused by carbon dioxide emissions per GDP unit in Russia. The damage was caused by motor fuel combustion, by transport in total 
and consumed by automobiles (this assessment was based on the data [12, 13]). An increase in emissions is a result of a continual increase, with the growth of the vehicle fleet, in the scale of consumption of fuel, simultaneously with the steady quality of fuels. Fuel consumption increases faster than the volume of GDP.

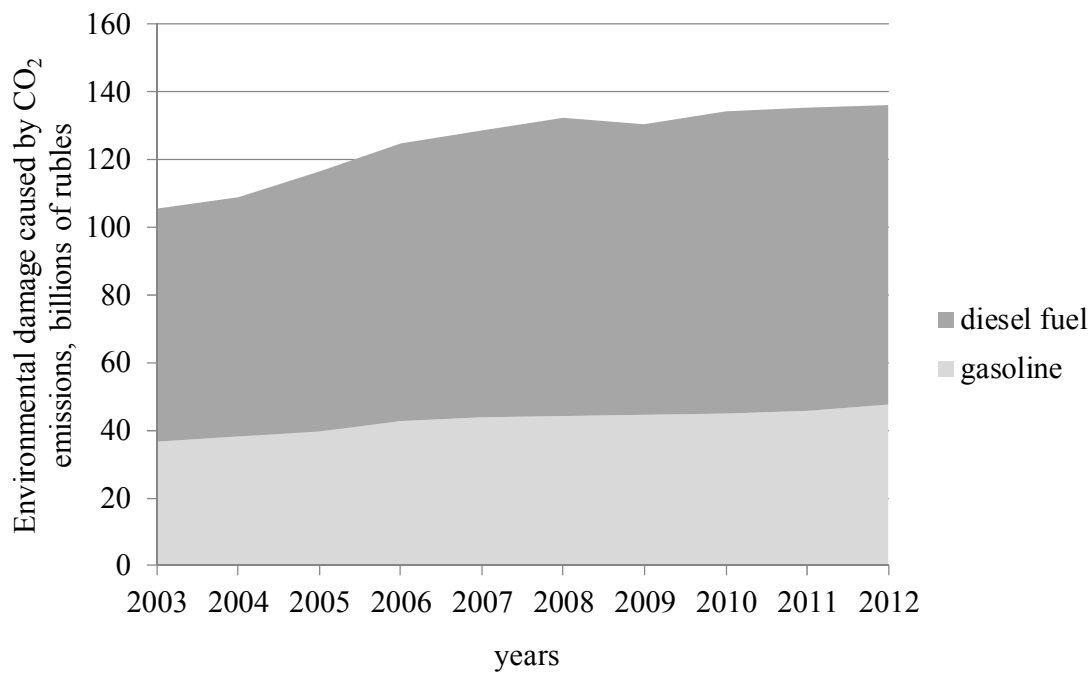

Figure 4: Dynamics of environmental damage caused by carbon dioxide emissions from motor fuels' combustion in comparable (as of 2010) prices.

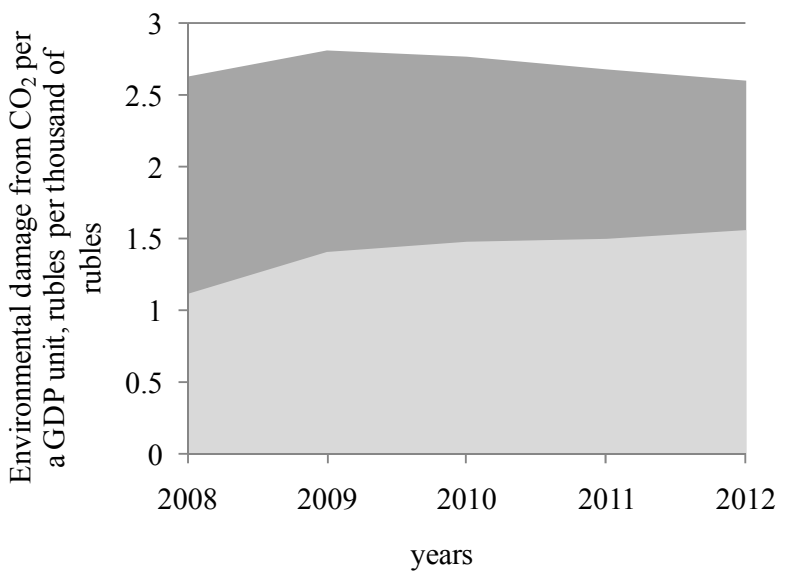

produced gasoline and diesel fuel index

gasoline and diesel fuel consumed by auto transport index

Figure 5: Dynamics of environmental damage caused by $\mathrm{CO}_{2}$ emission from motor fuel combustion, per GDP unit. 
A significant increase in the value of environmental damage from $\mathrm{CO}_{2}$ emissions per GDP unit in 2009 can be explained by the fact that, due to the global economic crisis which had an impact on Russia, motor fuel production decreased to a lesser extent than total GDP. The certain decrease in the value of environmental damage from $\mathrm{CO}_{2}$ emissions per GDP unit in 2010-2012, when calculating it on the basis of produced fuel, is related to the fact that fuel production increased less rapidly than the GDP.

Thereby, nowadays for Russia a typical feature is the increase in the emissions of carbon dioxide (along with the environmental damage from $\mathrm{CO}_{2}$ per GDP unit), caused by the consumption of gasoline and diesel fuel by auto transport, while a decrease is observed in the total amount of carbon dioxide emissions related to fuel and energy resources consumption. This tendency requires the elaboration of effective methods of economic stimulation of the participants of the transport process in order to reduce greenhouse gas emissions [11].

It should be noted that the main ways to reduce $\mathrm{CO}_{2}$ emissions by auto transport are by making the transition to alternative fuels and energy and through an increase in the fuel efficiency of automobiles with gasoline and diesel engines. Currently in Russia the priority task is to improve the quality of gasoline and diesel fuels, which are far behind their quality in developed countries. An improvement in fuel quality will reduce specific fuel consumption and will allow for a decrease in toxic pollutants emissions, as well as greenhouse gases emissions, caused by auto transport. Apart from this, there will be a decrease in the environmental damage caused by $\mathrm{CO}_{2}$ emissions from motor fuel combustion per GDP unit and gasoline and diesel fuel consumption will also decrease.

\section{Conclusion}

In consideration of the assessment of the environmental damage caused by organic fuel combustion, the negative impacts of the consequences of atmospheric oxygen consumption in technogenic processes and the negative impact to the environment caused by carbon dioxide emissions increases the reliability and objectiveness of such assessment.

The implemented analysis demonstrates that an increase in the fuel efficiency of auto transport in Russia is one of the priority lines to reduce the negative impact of fuel and energy resources consumption.

\section{References}

[1] BIO (2009), Study on the Implementation Effectiveness of the Environmental Liability Directive (ELD) and Related Financial Security Issues, Final Report, prepared by Bio Intelligence Service, Service Contract 070307/2008/516353/ETU/G.1, European Commission, Brussels, November 2009. http://ec.europa.eu/environment/legal/liability/pdf/ELD $\% 20$ Study $\% 20$ November\%202009.pdf. 
[2] Vershkov L.V., Groshev V.L., Gavrilov V.V., Prevented Environmental Damage Identification Methodology (main editor Chair of the State Committee for Environmental Protection Danilov-Danilyan, V.I), [in Russian], State Committee for Environmental Protection: Moscow, 1999.

[3] Magaril, E.R., Influence of the Quality of Engine Fuels on the Operation and Environmental Characteristics of Vehicles: monograph, [in Russian], KDU: Moscow, 2008.

[4] Magaril, E., Magaril R., Motor Fuels: the Problem of Energy Efficiency and Environmental Safety: monograph, [in Russian], LAP Lambert Academic Publishing GmbH \& Co: Saarbrücken, Deutchland, 2012.

[5] The State Program of the Russian Federation Energy Conservation and Increase of Energy Effectiveness until the Year 2020, http://rusecounion.ru/sites/default/files/energysave_2020.pdf.

[6] World Energy, http://www.worldenergy.ru/mode.1349-id.5062-type.html.

[7] BP Global Statistical Review of World Energy, 2012, http://www.bp.com.

[8] Financial Statistics and Macroeconomic Description of Countries, http://finstat.bozo.ru.

[9] International Energy Agency. World Energy Outlook 2008, http://www.worldenergyoutlook.org.

[10] Energy Technology Perspectives. Scenarios and Strategies to 2050, http://www.iea.org/techno/etp/etp10/English.pdf.

[11] Golubeva, A. \& Magaril, E., Improved economic stimulation mechanism to reduce vehicle $\mathrm{CO}_{2}$ emissions. WIT Transactions on the Built Environment, 130, pp. 485-489, 2013.

[12] Analytical Agency Autostat, http://www.autostat.ru.

[13] Analytical Bulletin Gas-and-Oil Producing and Refining Industry: Trends and Forecasts, 2012, № 9.http://www.riarating.ru.

[14] Russian Federal State Statistics Service, http://www.gks.ru.

[15] Magazine Behind the Wheel, [in Russian], http://www.zr.ru/content/news/516055-za_8_let_avtopark_rossii_vyros_pochti _v_1_5_raza. 